\title{
Sumber Kekuasaan Pimpinan DPRD di Pagar Alam (Studi Kasus Keterpilihan Dessy Siska Sebagai Wakil I)
}

\author{
Rekho Adriadi ${ }^{1}$; Fitri Anggriani² \\ ${ }^{1,2}$ Program Administrasi Publik, Fakultas Ilmu Sosial dan Politik, Universitas \\ Muhammadiyah Bengkulu, rekhoadriadi@umb.ac.id
}

\begin{abstract}
Abstrak
Sumber kekuasaan dalam keterpilihan Dessy Siska menjadi wakil I pimpinan DPRD Pagaralam menjadi perwujudan affirmative action di lembaga legislatif tingkat daerah . Tujuan dalam penelitian ini yaitu untuk mengetahui sumber kekuasaan apa yang mendorong Dessy Siska dalam memenangkan kursi wakil I pimpinan DPRD Pagaralam periode 2019-2024. Pada pemilu tahun 2019 di Pagaralam terdapat 25 anggota DPRD Kota Pagaralam dari jumlah anggota DPRD yang terpilih, Dessy Siska meraih suara terbanyak pada pemilu 2019. Faktor utama yang mendorong Dessy Siska menjadi wakil I pimpinan DPRD Pagaralam yaitu, sumber kekuasaan normatif, personal dan Ahli. Penelitian ini menggunakan metode penelitian kualitatif. Dalam penelitian ini data yang digunakan adalah data lisan maupun tulisan yang diperoleh melalui teknik wawancara, observasi, dan dokumentasi. Adapun teknik analisis data yang digunakan ialah tahap pengumpulan data, tahap reduksi data, tahap penyajian data, dan penarikan kesimpulan. Dalam sumber kekuasaan yang dikemukakan Charles F. Andrain terdapat lima indikator sumber kekuasaan. Dari lima indikator sumber kekuasaan tersebut Dessy Siska menggunakan sumber kekuasaan normatif dalam mendapatkan jabatannya sebagai wakil I pimpinan DPRD Pagaralam.
\end{abstract}

Kata kunci : Kekuasaan, Perempuan, Pimpinan.

\begin{abstract}
The source of power Dessy Siska in the election becomes Deputy I, leader of the Pagaralam DPRD (People's Representative Council) became the embodiment of affirmative action at the regional level legislative body. The purpose of this study is to find out what sources of power have driven Dessy Siska to win the first deputy I of the Pagaralam DPRD for the 2019-2024 period. In the 2019 election Pagaralam, there were 25 members of the Pagaralam City DPRD for the number of elected DPRD members, Dessy Siska gets the most votes in the 2019 election. The main factor that encourages Dessy Siska to become the deputy I of the Pagaralam DPRD, the source of normative, personal and expert power. This study used qualitative research methods. In this study, the data used were oral or written data obtained by interview, observation, and documentation techniques. The data analysis technique was used at the data stage, the data reduction stage, the data presentation stage, and the data collection. The sources of power by Charles F. Andrain, there are five indicators of sources of power. One of the five indicators of the source of power, Dessy Siska uses normative sources of power in her position as the deputy I of the Pagaralam DPRD.
\end{abstract}

Keywords : Leaders, Power, Women 


\section{Pendahuluan}

Keterlibatan perempuan di indonesia dalam politik khususnya dalam lembaga legislatif mulai memperoleh ruang sejak adanya affirmative action atau kebijakan strategis yang bersifat sementara merupakan bentuk deskriminasi positif yang dapat digunakan untuk membuka peluang dan kesempatan bagi kelompok minoritas hal ini merupakan perempuan (Soetjipto, 2005).

Maria Farida Indrati dalam kutipannya dari Hanna Pitkin, The of Representation 1967 mengemukakann, yaitu: 1) Perempuan mewakili setengah dari populasi dan mempunyai hak untuk setengah dari kursi legislatif; 2) Perempuan mempunyai pengalaman yang berbeda dari laki-laki (biologis maupun sosial); 3) Perempuan dan laki-laki mempunyai perbedaan kepentingan sehingga laki-laki tidak dapat mewakili perempuan; 4) Politisi perempuan memiliki peran penting untuk mendorong perempuan lain untuk mengikuti (Istiqomah et al., 2019).

Undang-Undang Dasar 1945 memberikan jaminan kedudukan yang sama bagi setiap warga negara (laki-laki dan perempuan) di muka hukum. Pada pasal 27 ayat 1 berbunyi: "Segala warga negara bersamaan kedudukan di dalam hukum dan pemerintahan dan wajib menjunjung hukum pemerintahan itu dengan tidak ada kecualinya.” Bab XA pasal 28A sampai dengan pasal 28J UUD 1945 juga secara tegas memberi jaminan terhadap HAM (Hak Asasi Manusia) perempuan. Hal ini ditegaskan dalam pasal 28D ayat (1) berbunyi: "Setiap orang yang berhak atas pengakuan, jaminan, perlindungan dan kepastian hukum yang adil dan perlakuan yang sama di hadapan hukum," dan ayat (3) mengatakan: "Setiap warga negara berhak mempunyai kesempatan yang sama dalam pemerintahan.” Kemudian pasal 28I ayat (2) menegaskan: "Setiap orang berhak bebas dari perlakuan yang bersifat diskriminasi atas dasar apapun dan berhak mendapatkan perlindungan terhadap perlakuan yang diskriminatif itu ".

Bahkan pasal $28 \mathrm{H}$ ayat (2) menegaskan keberpihakan negara untuk memberlakukan kebijakan yang bersifat afirmatif sebagai berikut: "Setiap orang berhak mendapatkan kemudahan dan perlakuan khusus untuk memperoleh kesempatan dan manfaat yang sama guna mencapai persamaan dan keadilan”. 
Banyak ketentuan dalam undang-undang serta peraturan-peraturan yang memberikan perlindungan yuridis terhadap perempuan.

Dikutup dari Farida dalam (Farida, 2011) Pemerintah Indonesia telah mengesahkan konvensi penghapusan segala bentuk diskriminasi terhadap perempuan atau Convention on the Elimination of All froms Driscimination Against Women (CEDAW) melalui Undang-Undang (UU) Nomor 7 Tahun 1984 pasal 7 mengatur juga hak-hak politik perempuan, menjamin persamaan antara perempuan dengan laki-laki dalam hal: 1) Hak untuk dipilih dan memilih; 2) Hak untuk berpartisipasi dalam perumusan kebijakan pemerintah dan implementasinya; 3) Hak untuk memegang jabatan dalam pemerintah dan melaksanakan segala fungsi empat pemerintah di semua tingkat; 4) Hak untuk berpartisipasi dalam organisasi atau perkumpulan non pemerintah yang berhubungan dengan kehidupan masyarakat dan politik.

Kebijakan di atas membuka ruang partisipasi perempuan ke dalam ranah politik. Salah satu bentuk affirmative action adalah kebijakan kuota yang diatur dalam Undang-Undang Nomer 7 Tahun 2017 tentang pemilihan umum anggota Dewan Perwakilan Rakyat (DPR), Dewan Perwakilan Rakyat Daerah (DPRD), dan Dewan Perwakilan Daerah (DPD) Yang Berbunyi: "peserta pemilu untuk memilih anggota DPR, DPRD adalah partai politik yang menyertakan sekurang-kurangnya 30\% keterwakilan perempuan pada kepengurusan partai politik" (Marlena, 2019).

Undang-Undang tersebut secara tidak langsung membentuk salah satu akomodasi politik atas pentingnya kesetaraan gender bagi kalangan perempuan dalam wilayah politik sekaligus memberi ruang yang lebih besar untuk perempuan dalam pembangunan bangsa. Representasi perempuan yang memadai di legislatif akan sangat dibutuhkan, hal ini dapat dilihat dalam kondisi legislatif sebelumnya di mana keterwakilan perempuan sangat rendah sehingga kepentingan kaum perempuan menjadi terabaikan.

Kuota 30\% keterwakilan perempuan diharapkan mampu mengeliminasi hal tersebut untuk memberikan kesempatan kepada kaum perempuan terlibat lebih banyak di ranah politik. Namun dalam kenyataannya Undang-Undang ini sepertinya belum diterapkan maksimal, selain itu juga banyaknya persaingan untuk 
memperebutkan kursi legislatif menyebabkan keterwakilan perempuan mengikuti peraturan persaingan yang alamiah (Mukarom, 2008).

Secara normatif keberadaan perempuan di legislatif diharapkan bisa mempengaruhi kinerja lembaga legialatif sehingga lebih berpihak pada kepentingan perempuan. Upaya ini menurut Lovenduski dan Karam dapat dilakukan dengan empat cara (Lovenduski \& Karam, 2002), yaitu: 1) menyangkut bidang institusional atau prosedural, yaitu membuat parlemen lebih ramah kepada perempuan melalui langkah-langkah yang dapat menunjukan kepedulian gender dan menghasilkan peraturan-peraturan yang lebih ramah ke pada perempuan; 2) berkenaan dengan representasinya. Artinya jaminan keberlanjutan dan peningkatan akses perempuan ke parlemen dengan mendorong dan mendukung kandidat-kandidat perempuan lain untuk berjuang masuk menjadi anggota parlemen, mengupayakan agar anggota perempuan mendapat posisi penting di parlemen, mengubah undang-undang pemilihan umum dan kampanye, serta mengajukan legislasi kesetaraan jenis kelamin; memberi dampak atau pengaruh terhadap keluaran (output). Hal ini berkaitan dengan upaya melakukan "feminisasi" legislasi dengan memastikan bahwa semua perundang-undangan atau semua produk kebijakan yang dibuat oleh lembaga legislatif benar-benar mempertimbangkan kepentingan dan kebutuhan perempuan (gender sensitive); 4) mengubah wacana, yaitu menjadikan perspektif perempuan dalam perdebatan di parlemen sebagai suatu hal yang wajar dan mendorong perubahan sikap publik terhadap perempuan. Upaya ini dapat didukung oleh peran media massa dan publik, sehingga dapat meningkatkan kapasitas anggota legislatif perempuan dalam debat publik dan meningkatkan kepedulian mereka pada isu-isu perempuan.

Salah satu upaya yang bisa dilakukan oleh kaum perempuan adalah dengan membuktikan sumbangsih signifikan mereka dalam semua proses politik yang berlangsung di legistatifDi perlukan dukungan partai politik bagi calon anggota legislatif perempuan, serta memberi pendidikan politik kritis bagi perempuan. Pada akhirnya keterwakilan perempuan di dunia politik mampu meningkat dan bersaing dengan kaum Laki-laki. 
Pada pemilu tahun 2014 di Pagaralam, jumlah anggota dewan di DPRD Pagaralam terdapat 25 orang yang terpilih, dari 25 anggota dewan yang terpilih hanya 5 orang anggota perempuan atau sebesar $20 \%$ dari jumlah keanggotaan yang berhasil duduk di DPRD Pagaralam. Dari jumlah anggota perempuan yang hanya 5 orang pada pemilu 2014 menunjukkan bahwa keterwakilan perempian di legislatif belum mencapai 30 persen.

Sementara pada pemilu 2019 anggota dewan di Pagaralam masih berjumlah 25 orang. Keterwakilan perempuan pada pada pemilu 2019 mengalami penurunan menjadi 4 persen artinya lebih banyak periode sebelumnya, walaupun menurun 16\% yang pada awalnya mencapai 20\%, pada pemilu tahun 2019 . Terdapat 2 diantaranya menjadi pimpinan DPRD Pagarlam pada pemilu 2019. Salah satunya Dessy Siska dari Partai Gerakan Indonesia Raya (Gerindra) yang menjabat sebagai Wakil Ketua I DPRD Pagaralam. Dessy Siska memiliki latar belakang yang sangat berpengaruh di Pagaralam khususnya daerah Pagaralam Utara.

Pasca keterpilihannya menjadi wakil I pimpinan DPRD Pagaralam dalam pemilu 2019 di Pagaralam, kemenangan ini merupakan fenomena tersendiri dalam konteks kesetaraan gender di Pagaralam, karena untuk pertama kalinya wakil I pimpinan DPRD Pagaralam diduduki oleh perempuan. Fenomena ini penting untuk di analisis secara lebih mendalam. Studi mengenai sumber-sumber kekuasaan sebelumya telah dilakukan oleh Zuada, Adriadi \& Kadi (2020) yang menemukan bahwa kekuasaan yang digunakan dalam memperoleh kursi DPRD dan DPR RI bersumber dari ekonomi, normatif dan personal.

Penelitian ini bertujuan untuk mengetahui sumber kekuasaan apa yang digunakan oleh Dessy Siska dalam mendapatkan kedudukannnya dengan fokus pada sumber kekuasaan menurut Charles F andrain (Andrain, 1992) yang terdiri dari lima sumber kekuasaan, yaitu sumber kekuasaan fisik, sumber kekuasaan ekonomi, sumber kekuasaan normatif, sumber kekuasaan personal dan sumber kekuasaan ahli. Kekuasaan merupakan salah satu kajian penting. Keterkaitan antara politik dan kekuasaan menjadikan setiap pembahasan tentang politik, selalu melibatkan kekuasaan didalamnya. 


\section{Metode}

Penelitian ini menggunakan metode kualitatif dengan pendekatan penelitian dilakukan melalui studi deskriptif. Penelitian ini dilaksanakan di Daerah Dapil III Pagaralam Utara, Kota Pagaralam. Penelitian yang digunakan oleh peneliti adalah penelitian deskriptif kualitatif. Menurut Sugiyono dalam (Sugiyono, 2010) menjelaskan bahwa penelitian deskriptif adalah penelitian yang dilakukan untuk mengetahui nilai variabel mandiri, baik satu variabel atau lebih (indevenden) tanpa membuat perbandingan atau menghubungkan antara satu dengan variabel yang lain.

Adapun teknik pengumpulan data dalam penelitian ini yaitu observasi, wawancara dan dokumentasi. Observasi dilakukan dengan cara pengamatan langsung di Daerah kemenangan pemilihan Dapil Dessy Siska, sedangkan wawancara yang dilakukan dengan menyiapkan terlebih dahulu pertanyaanpertanyaan peneliti atau pedoman wawancara yang sesuai dengan permasalahan yang akan diteliti nantinya, dan yang akan ditanyakan pada informan. Analisis data yang digunakan dalam penelitian ini adalah adalah teknik analisis data menurut Miles dan Huberman dalam (Kuckartz, 2019) yang mana meliputi tahap tahap seperti reduksi data, penyajian data dan penerikan kesimpulan dan verifikasi.

Kemudian, fokus dalam penelitian ini adalah analisis kepemimpinan perempuan di Legislatif studi kasus pimpinan DPRD Kota Pagaralam. Konsep atau teori yang digunakan oleh penulis yaitu teori kekuasaan dari Charles F. Andrian (Andrain, 1992) dengan fokus pada Kekuasaan Normatif yang meneliti fenomena agama atau tradisi.

\section{Hasil dan Pembahasan}

Hasil Pemilu 2019 telah menetapkan keanggotaan DPRD Kota Pagaralam sebanyak 25 orang termasuk jumlah ini didasarkan pada jumlah penduduk Kota Pagaralam yang mencapai 100.000 sampai 170.000 jiwa. 25 Anggota DPRD masing-masing berasal dari partai sebagai berikut:

Tabel 1. Keanggotaan DPRD Pagaralam 2019-2024

\begin{tabular}{|c|c|c|}
\hline No & \multicolumn{1}{|c|}{ Nama Partai } & Jumlah \\
\hline 1. & Partai Nasional Demokrat & 3 Orang \\
\hline
\end{tabular}




\begin{tabular}{|c|l|l|}
\hline 2. & Partai Indonesia Raya & 3 Orang \\
\hline 3. & Partai Golongan Rakyat & 3 Orang \\
\hline 4. & Partai Keadilan Sjahtera & 3 Orang \\
\hline 5. & Partai Demokrat Indonesia Perjuangan & 3 Orang \\
\hline 6. & Partai Kebangkitan Bangsa & 2 Orang \\
\hline 7. & Partai Demokrat & 2 Orang \\
\hline 8. & Partai Hati Nurani Rakyat & 2 Orang \\
\hline 9. & Partai Persatuan Pembangunan & 1 Orang \\
\hline 10. & Partai Bulan Bintang & 1 Orang \\
\hline 11 & Partai Amanat Nasional & 1 Orang \\
\hline 12 & Partai Keadilan dan Persatuan Indonesia & 1 Orang \\
\hline
\end{tabular}

Sumber: KPU Kota Pagaralam (20 Januari 2020)

Dari rincian 25 kursi yang ada, hanya 12 Partai Politik (Parpol) berhasil mendapatkan kursi legislative kota Pagar Alam. Sedangakan berdasarkan metode sainte lague menunjukan adanya kekosongan 2 kursi di satu Dapil. Pada pemilu kali ini 3 besar perolehan suara Parpol didapat oleh Partai NasDem dengan perolehan suara 5.153 suara, Partai Gerindra dengan perolehan suara 3.330 suara, dan Partai Golkar dengan jumlah suara 3.703 suara. Dari hasil tersebut unsur pimpinan DPRD Pagaralam lima tahun kedepan akan menjadi milik ketiga Parpol tersebut.

Berdasarkan pemilu 2019, untuk pertama kalinya dalam sejarah Kota Pagaralam. Lembaga legislatif menepatkan seorang perempuan di posisi pimpinan DPRD Kota Pagaralam, Jenni shandiyah dari Partai NasDem dan Wakil Ketua I di duduki oleh Dessy siska dari Partai Gerindra. Jenni shandiyah memperoleh hasil suara 2.376 suara sedangkan Dessy siska memperoleh suara 2.671, partai merekapun meraih perolehan suara tertinggi partai mereka memperoleh suara terbanyak.

Berdasarkan gambaran data mengenai sumber kekuasaan perempuan di pimpinan DPRD Pagaralam, khususnya di daerah Dapil III Pagaralam Utara. Diketahui pada Kecamatan Pagaralam Utara memiliki 10 Kelurahan dan 138 TPS, adapun perolehan suara seluruh partai politik di Dapil III Pagaralam Utara, dapat dilihat dari tabel dibawah:

Tabel 2. Perolehan Suara Partai Politik

\begin{tabular}{|l|c|c|}
\hline No & Partai Politik & Perolehan Suara \\
\hline 1. & PKB & 1.771 \\
\hline
\end{tabular}




\begin{tabular}{|l|c|c|}
\hline 2. & Gerindra & 3.330 \\
\hline 3. & PDIP & 2.050 \\
\hline 4. & Golkar & 3.677 \\
\hline 5. & NasDem & 5.153 \\
\hline 6. & Garuda & 0 \\
\hline 7. & Berkarya & 95 \\
\hline 8. & PKS & 2.721 \\
\hline 9. & Perindo & 83 \\
\hline 10. & PPP & 1.553 \\
\hline 11. & PSI & 59 \\
\hline 12. & PAN & 731 \\
\hline 13. & Hanura & 96 \\
\hline 14. & Demokrat & 693 \\
\hline 15. & PBB & 1.798 \\
\hline 16. & PKPI & 2.466 \\
\hline
\end{tabular}

Sumber: KPU Kota Pagaralam (20 Januari 2020)

Dari perolehan suara tersebut terdapat 7 kursi DPRD Kota Pagaralam Priode 2019-2024 Dapil III Pagaralam Utara diantaranya: 1) NasDem (Jenny Shandiyah) total suara 5.153, 2) Golkar (Efsi) total suara 3.703, 3) Gerindra (Dessy Siska) total suara 3.330, 4) PKS (Firmansyah) tota suara 2.721, 5) PKPI (Kasno Pandri) total suara 2.466, 6) PDIP (Tanhar) total suara 2.050, dan 7) PBB (Masagus Toyeb) total suara 1.798 .

Dessy siska seorang ibu rumah tangga yang menetap di Kota Palembang selama menjadi ibu rumah tangga pekerjaan Dessy siska hanya membantu suaminya dalam mengelola pekerjaan. Dessy siska adalah lulusan sarjanah ekonomi, yang menarik dalam seorang Dessy siska yaitu gelar yang dia miliki selama bertahun-tahun tidak pernah digunakannya dalam bekerja ataupun hal yang lainnya selama bertahun-tahun.

Tahun 2014 awal mula Dessy siska terjun ke politik dan pada tahun tersebut Dessy siska menggunakan gelarnya yang bertahun-tahun tidak digunakannya. Dessy siska mencalonkan dirinya di Dapil III Pagaralam Utara yang juga tempat tinggalnya. Adpun faktor yang mendukung Dessy siska dalam memenangkan kursi DPRD pada tahun 2014 yaitu faktor keluarganya, banyak masyarakat Pagaralam mengatakan jika ayah Dessy siska (Enal Nangljik) adalah keturunan kerajaan, ayah Dessy siska merupakan cucu dari pangeran yang ada di 
Pagaralam pada saat itu. Hal ini dikatakan oleh Ridho Muhaimin Ketua PPS Kelurahan Dapil III Pagaralam Utara dalam (Anggraini, 2020):

"Memang banyak masyarakat mengatakan kalo keluarga buk dessy masih keturunan bangsawan ayahnya yang masih berketurunan dari kerajaan berita ini juga masyarakat sudah mengetahuinya, tak jarang kalo masyarakat memilih buk dessy karna latar belakang orang tuanya"

Dari gambar spanduk Dessy Siska tersebut terlihat jelas bahwa beliau menggunakan nama ayahnya saat pemilu, karna nama ayahnya sangat berpengaruh di Pagaralam maka dari itu Dessy siska mempengaruhi masyarakat agar memilihnya dengan menggunakan latar belakang ayahnya yang juga dipercayai oleh masyarakat Pagaralam masih mempunyai keturunan kerajaan.

Gambar 1. Spanduk Hj. Dessy Siska

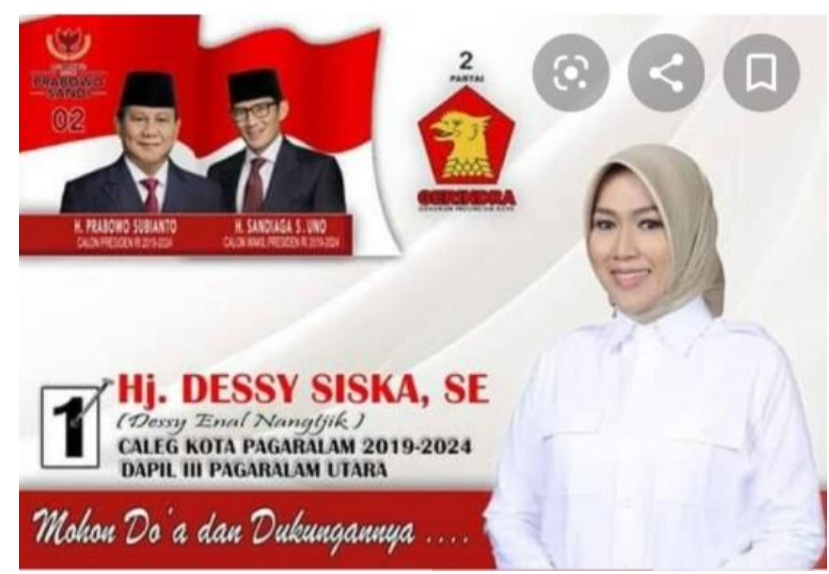

Sumber: Dokumentasi Peneliti 2020

Dari gambar spanduk Dessy siska tersebut terlihat jelas bahwa beliau menggunakan nama ayahnya saat pemilu, karna nama ayahnya sangat berpengaruh di Pagaralam khususnya daerah Pagaralam Utara oleh karena itu Dessy siska menjadikan peluang besar untuk kemenangannya pada saat pemilu berlangsung. Karena masyarakat Pagaralam banyak mengatakan jika ayah dari Dessy Siska masih keturunan Kerajaan di Pagaralam pada saat itu.

Dari latar belakang ayahnya lah Dessy siska memenangkan jabatan sebagai anggota DPRD Kota Pagaralam pada tahun 2014 pada pemilu tahun tersebut Dessy siska mendapatkan perolehan suara 1.087 dan partainya 
memperoleh suara 4.310 perolehan suara tersebut membawa Dessy siska duduk dikursi DPRD Kota Pagaralam.

Pada pemilu 2019 Dessy siska mencalonkan dirinya kembali, pada tahun tersebut dessy mnedpatkan perolehan suara tertinggi di Dapil III Pagaralam Utara. Hal ini dikatakan jika masyarakat pada awal jabatan dessy pada tahun 2014 masyarakat menilai jika dessy seorang yang dermawan dan juga peduli dengan masyarakat dan juga masyarakat banyak sekali memuji seorang Dessy siska, walau pada awal pencalonnya masyarakat memilihnya karna faktor keluarganya, akan tetapi pada pemilu tahun 2019 ini masyarakat sudah mengenal baik dessy siska sebgai panutan yang bisa di contoh.

Latar belakang ayah Dessy siska yaitu Bapak Zainal Abidin yang merupakan anak dari Nangljik dan kakeknya bernama Khidmat Sukma Jaya. Kakeknya merupakan penguasa di Daerah Alun Dua Pagaralam Utara pada zaman dulu, kakeknya sangat terkenal sebagai penguasa di daerah tersebut. Hal ini di benarkan oleh Ibu Yanti Moeryadi Zainal, ibunda dari Dessy siska dalam (Anggraini, 2020) beliau mengatakan sebagai berikut:

"Kalo keturunan kerajaan tidak, kakeknya bernama Khidmat Sukma Jaya, dan mempunyai anak namanya Nangljik sedangkan suami saya bernama Zainal Abidin anak dari Nanjlik selaku mertua saya, kakeknya suami saya sebenarnya seorang penguasa di daerah Alun Dua pada zaman itu".

Pernyataan tersebut menyampaikan informasi penting yang sejak dulu di percayai masyarakat Pagaralam bahwa keluarga Dessy Siska masih memiliki darah kerajaan. Pernyataan dari ibunda Dessy pun bisa dijadikan kebenarannya bahwa latar suaminya yaitu bapak Zainal Abidin bukan keturunan dari kerajaan melainkan keturunan dari seorang penguasa di daerah Alun Dua Kota Pagaralam. Sampai saat ini keluarganya sangat dihormati di daerah Pagaralam khusunya daerah Pagaralam Utara.

Kemudian pada tahun 2019 Dessy siska dalam (Anggraini, 2020) menjelaskan bahwa mendapatkan kedudukan sebagai wakil ketua I DPRD Kota Pagaralam, bisa dikatakan Dessy siska memenangkan jabatannya karna faktor ayahnya yang seorang penguasa di daerah Pagaralam Utara wajar saja jika Dessy 
sisaka mendapatkan perolehan suara tertinggi di dapil III Pagaralam Utara karena masyarakat masih memndang keluarga Dessy siska terutama ayah dari seorang Dessy siska. Dari hasil pengumpulan data serta observasi peneliti dapat dikatakan jika Dessy siska mendapatkan jabatannya dengan menggunakan sumber kekuasaan normatif.

\section{Kesimpulan}

Berdasarkan dari hasil pembahasan di atas, sumber kekuasaan yang digunakan Dessy Siska dalam memndapatkan kedudukannya sebagai wakil I pimpinan DPRD Pagaralam karena latar belakang ayahnya yang juga seorang cucu dari penguasaan di daerah Alun Dua Kota Pagaralam, karena itu Dessy siska menggunakan latar belakang ayahnya untuk mendapatkan kedudukannya saaat ini. Dalam hal ini Dessy siska menggunakan sumber kekuasaan normatif untuk mempengaruhi masyarakat pagaralam agar memilihnya

\section{Referensi}

Zuada, LH., Adriadi, R., \& Kadir, A. (2020). Women's Power and Electability in Southeast Sulawesi: A Case Study for Provincial and National Legislative Candidate. Politik Indonesia: Indonesian Political Science Review, 5(1).

Andrain, C. F. (1992). Kehidupan Politik dan Perubahan Sosial. Yogyakarta: Tiara Wacana.

Anggraini, F. (2020). Analisis Kepemimpinan Perempuan Di Legislatif (Studi Kasus Pimpinan Dprd Kota Pagaralam). Skripsi Administrasi Publik Universitas Muhammadiyah Bengkulu.

Farida, E. (2011). Implementasi Prinsip Pokok Convention On The Elimination Of All Forms Discrimination Againts Women (CEDAW) di Indonesia. Masalah-Masalah Hukum, 40(4), 443-453.

Istiqomah, S. I. P., Miftah, A. A., \& Fuhaidah, U. (2019). Peran Kpu Terhadap Partisipasi Calon Legislatif Perempuan Dalam Menghadapi Tahun Politik Periode 2019 Kota Jamb. UIN Sulthan Thaha Saifuddin. 
Kuckartz, U. (2019). Qualitative content analysis: From Kracauer's beginnings to today's challenges. Forum Qualitative Sozialforschung/Forum: Qualitative Social Research, 20(3).

Lovenduski, J., \& Karam, A. (2002). Perempuan di Parlemen: Membuat suatu Perbedaan. Dalam: J. Ballington, S. Kadirgamar-Rajasingham. Perempuan Di Parlemen: Bukan Sekedar Jumlah.

Marlena, H. (2019). Analisis Keterwakilan Perempuan Di DPRD Seluma (Studi Implementasi Undang-Undang Nomor 7 Tahun 2017 Tentang Pemilu). Jurnal Manajemen Publik \& Kebijakan Publik (JMPKP), 1(1), 63-75.

Mukarom, Z. (2008). Perempuan dan Politik: Studi Komunikasi Politik tentang Keterwakilan Perempuan di Legislatif. MediaTor: Jurnal Komunikasi, 9(2), 257-270.

Soetjipto, A. W. (2005). Politik perempuan bukan gerhana: esai-esai pilihan. Penerbit Buku Kompas.

Sugiyono, D. (2010). Metode penelitian kuantitatif dan R\&D. Bandung: Alfabeta. 